\title{
THE ROSTRAL EPIDURAL RETE MIRABILE OF THE LLAMA AS A PLACE OF RETROGRADE TRANSPORT OF VARIOUS SUBSTANCES - ANATOMICAL BASICS
}

\author{
Maciej Zdun ${ }^{1}$, Arkadiusz Grzeczka ${ }^{1}$, Marcin Zawadzki ${ }^{1}$, Hieronim Frąckowiak ${ }^{1}$
}

\begin{abstract}
The aim of this study was to analyse the structure of the rostral epidural rete mirabile in the llama. Some specimens were prepared by injecting stained chemically cured acrylic into the bilateral common carotid arteries. After about 1 month received vascular corrosion casts on the bone scaffold. Some specimens made using red and blue latex introduced into the bilateral common carotid arteries and the bilateral external jugular vein. The rostral epidural rete mirabile is a well-developed, bilateral structure composed of numerous arteries, which are multiply anastomosed with each other. The cranial section of the rete is asymmetrical. Its lateral part is much better developed, because there are rostral branches to the rostral epidural rete mirabile at this point. The arterial vessels are not accompanied by homonymous veins. However, the arteries of the rostral epidural rete mirabile are accompanied by venous vessels of the cavernous sinus. That rete plays an important role in selective brain cooling, the conservation of body water, and retrograde transport of neurotransmitters. $\mathrm{CO}, \mathrm{GnRH}$, beta-endorphin, progesterone, testosterone, oxytocin, LHRH and dopamine diffuse from the venous blood of the cavernous sinus to the arterial blood of the rostral epidural rete mirabile.
\end{abstract}

Running title: The rostral epidural rete mirabile of the llama

Keywords: carbon monoxide, even-toed ungulates, neurotransmitters, RERM 


\section{Introduction}

The arterial system of the head of even-toed ungulates is characterised by the presence of the rostral epidural rete mirabile. Due to the location of this rete in the cavernous sinus, it plays an important role in selective brain cooling [1-3], the conservation of body water [4], and retrograde transport of neurotransmitters $[5,6]$. The Artiodactyla order (even-toed ungulates) includes numerous species of animals inhabiting almost all climatic zones of our planet, which can adapt to various environmental conditions, e.g. animals of the Cameliformes, Ruminantia, and Suiformes suborders [7]. The construction of the rostral epidural rete mirabile in selected representatives of ruminants has been well described [8]. Numerous authors describing the vessels of the encephalon base in Cameliformes mentioned the rete $[9,10]$, but did not describe it in detail. There has been a description of the morphometric characteristics of the rostral epidural rete mirabile of the dromedary - a representative of the Old World camelids [11], but this structure has not been described in any representative of the New World camelids. Each of the suborders of even-toed ungulates differs in the structure of the rostral epidural rete mirabile.

As there have been numerous scientific publications on the functional nature of this vascular region in species of the Ruminantia and Suiformes suborders, the aim of this study was to analyse the structure of the rostral epidural rete mirabile in the llama - a representative of the Cameliformes suborder. This study may be useful for physiological examinations of other suborders of even-toed ungulates.

\section{Material and methods}

The study was conducted on 5 specimens of the llama of the Llama subfamily, Cameliformes suborder. The research material was collected from private breeders posthumously.

Three specimens were prepared by injecting stained chemically cured acrylic DURACRYL ${ }^{\circledR}$ PLUS (SpofaDental, Jičín) into the bilateral common carotid arteries. The specimens were cured after about $20 \mathrm{~min}$. Next, the material was enzymatically macerated with Persil powder (Henkel, Düsseldorf) at $42^{\circ} \mathrm{C}$ for about 1 month. The procedure resulted in vascular corrosion casts on the bone scaffold. Two specimens were prepared with another method. Liquid LBS 3060 red latex was introduced into the bilateral common carotid arteries. Moreover, liquid blue latex was introduced into the bilateral external jugular vein. Next, the material was immersed in a $5 \%$ formalin solution, where it hardened after 7 days. Next surgical instruments were used to manually dissect the arteries and to obtain images of the blood vessels on the tissues of individual animals. The names of the anatomical structures were standardised according to the Nomina Anatomica Veterinaria [12].

\section{Results}

Blood reaches the rostral epidural rete mirabile (rete mirabile epidurale rostrale) through the paired common carotid artery (arteria carotis communis) and the external carotid artery (arteria carotis externa), which is an extension of the former vessel. The internal carotid artery (arteria carotis interna) branches off in the place where the common carotid artery becomes the external carotid artery.

The internal carotid artery passes through the jugular foramen and joins the rostral epidural rete mirabile. Moreover, this rete is composed of numerous rostral branches to the rostral epidural rete mirabile (rami rostrales ad rete mirabile epidurale rostrale) and the caudal branch to the rostral epidural rete mirabile (ramus caudalis ad rete mirabile epidurale rostrale). The rostral branches branch from the maxillary artery (arteria maxillaris) and the external ophthalmic artery (arteria ophthalmica externa). The caudal branch was very thin and it was lacking from one specimen bilaterally and one specimen unilaterally.

The rostral epidural rete mirabile is a well-developed, bilateral structure located on the corpus of the basisphenoid bone, on the lateral sides of the hypophysial fossa (Fig. 1). It is composed of numerous arteries, which are multiply anastomosed with each other. The shape of the rostral epidural rete mirabile resembles an elongated oval. The cranial section of the rete is asymmetrical. Its lateral part is much better developed, because there are rostral branches to the rostral epidural rete mirabile at this point. At the half-length of the cross-section of the rostral epidural rete mirabile its shape is the most similar to an oval and the rete is composed of tiny vessels of similar diameters. The bilateral retes were connected by numerous vessels in the caudal section. The number of vessels in the rete ranged from 48 to 61 .

The rostral cerebral artery (arteria cerebri rostralis) and the caudal communicating artery (arteria communicans caudalis) emerge from the rete. These vessels are the main arteries forming the cerebral arterial circle (circulus arteriosus cerebri).

The arterial vessels are not accompanied by homonymous veins. However, the arteries of the rostral epidural rete mirabile are accompanied by venous vessels of the cavernous sinus (sinus cavernosus). The rostral epidural rete mirabile is embedded in the cavernous sinus. There are numerous small spaces, resulting in a spongy structure of this sinus. These spaces are filled with vessels of the rostral epidural rete mirabile. 


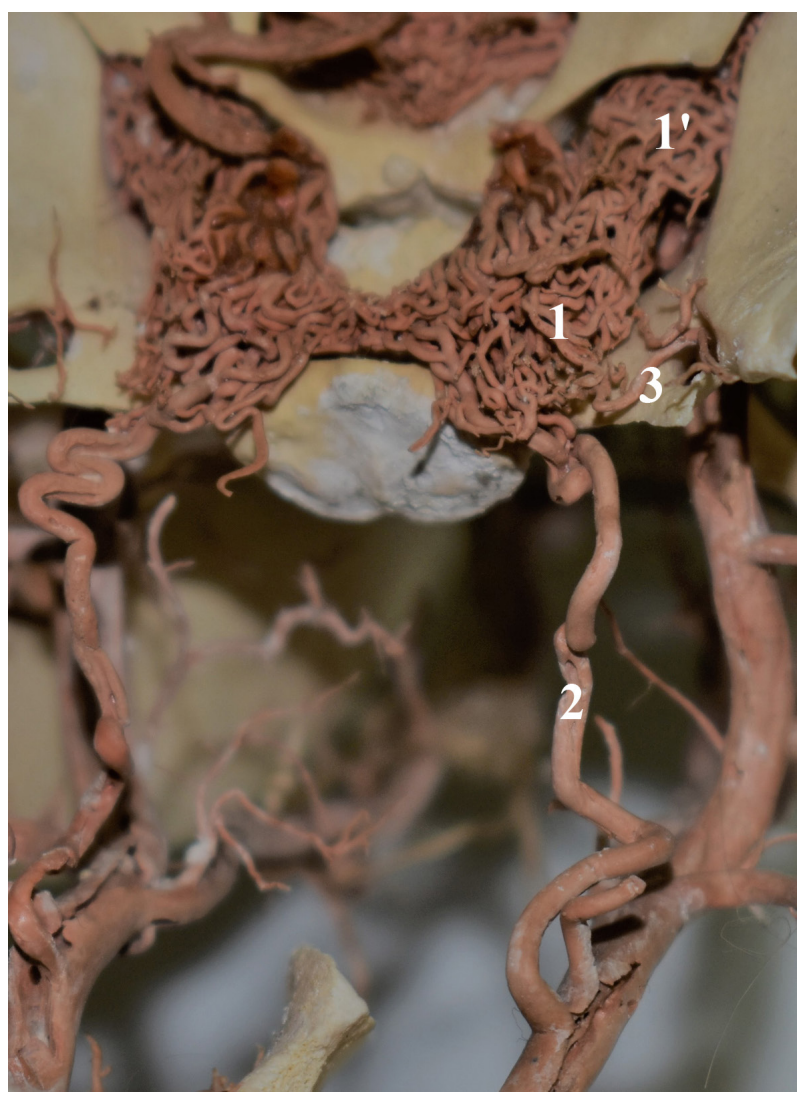

FIGURE 1 Corrosion cast of the rostral epidural rete mirabile

1- rostral epidural rete mirabile

$1^{\prime}$ - rostral part of the rete mirabile with rostral branches to the rete

2 - internal carotid artery

3 - caudal branch to the rete mirabile

\section{Discussion}

The internal carotid artery is one of the vessels supplying blood to the rostral epidural rete mirabile in Cameliformes. It has been described in the Bactrian camel, dromedary, llama, and guanaco [9-11]. The maxillary artery, which is a direct extension of the external carotid artery, splits into the caudal branch to the rostral epidural rete mirabile and the rostral branches to the rete. The rostral branches to the rete branching from the maxillary artery and the external ophthalmic artery are the main vessels supplying blood to the rete in Cameliformes [9-11]. Apart from that, there is a weak caudal branch to the rostral epidural rete mirabile, which Al Aiyan et al. defined as the middle meningeal artery [10].

A cross-section of the rostral epidural rete mirabile revealed a bundle of tiny vessels of similar diameter. According to Simoens et al. [13], the rete has a bipolar structure. Researchers have been interested in the function of this rete for a long time. According to some authors, the rostral epidural rete mirabile regulates the blood flow [14]. However, Dieguez et al. [15-17] observed that the arteries forming the rete did not respond to adrenergic stimulation and concluded that they did not actively regulate the flow of blood to the brain. O'Brien and
Bourke [18] also concluded that the rostral epidural rete mirabile was structurally incapable of reducing the pressure of blood flowing to the brain. Regardless of whether the rete regulates the flow of blood to the brain or not, many authors see its physiological role in the selective brain cooling mechanism. This mechanism was described by Hayward and Backer in 1969 [1]. Its essence is to cool the warmer blood flowing through the arteries to the brain. These arteries form a vast pool in numerous vessels of the rete washed by cooler blood returning from the nasal cavity and flowing through the cavernous sinus $[1-3,13]$. As a result, during muscular effort the animal can maintain the temperature of its brain at $40.5^{\circ} \mathrm{C}$. Research conducted on Dorper sheep also proved the importance of selective brain cooling for the conservation of body water [19].

Apart from that, the rostral epidural rete mirabile together with the cavernous sinus are responsible for the retrograde transport of neurotransmitters, which is a lesser-known fact. Studies on pigs and sheep have shown that there is GnRH, beta-endorphin, progesterone or testosterone [5], oxytocin $[20]$, and dopamine [21,22] diffusion from the venous blood of the cavernous sinus to the arterial blood of the rostral epidural rete mirabile. Arterial blood 
is not mixed with venous blood, because both the arterial and venous systems are not devoid of the vessel walls. The exchange is possible due to the fact that the outer layers of veins and arteries connect into the common tunica adventitia [23]. The inner muscular layer of arterioles is reduced to 3-5 layers of muscle cells. Venous blood is separated from arterial blood by five or six relatively thin vascular layers [6]. The mechanisms regulating the penetration of neurotransmitters are not fully understood. There are differences related to the oestrus cycle. The countercurrent transfer of beta-endorphin takes place during the early luteal phase in the breeding season, but not during seasonal anoestrus. Studies showed that the efficiency of the permeability of oxytocin [20] and LHRH in pigs [6, 24] depends on the day of the oestrous cycle. Moreover, there may a link between the LH and oestradiol concentration in blood [6]. Another role of the cavernous sinus system in the rete mirabile is to transport the regulator of neurogenic carbon monoxide (CO). The energy from visible light stimulates the production of carbon monoxide by the retina, which penetrates through the cavernous sinus into the vessels of the rostral epidural rete mirabile, and causes changes in the activity of the brain [25]. Being a physiological regulator, carbon monoxide has decisive influence on the brain function as the main biological clock It alters the expression of the Per and Cry genes, which modulate the circadian rhythm and seasonal cycles [26]. According to available scientific publications, the rostral epidural rete mirabile in Cameliformes is more strongly developed than in the other suborders $[8,10]$. This increases the contact surface between the arterial and venous systems. It may be an adaptation to its function. However, physiological tests are necessary to confirm this hypothesis.

\section{Conclusions}

The rostral epidural rete mirabile, formed from numerous anastomotic arteries, is a well-developed, even structure, with an elongated oval shape. Its rostral section is particularly well- developed. The vessels of the rete are embedded in the cavernous sinus. The rostral segment is particularly well-developed due to the strong extensive rostral branches to the rete.

\section{Ethical approval}

The research related to animal use has been complied with all the relevant national regulations and institutional policies for the care and use of animals. As the research material was collected posthumously, no Ethical Committee approval is needed for this study.

\section{Acknowledgements \\ Not applicable.}

\section{Corresponding author}

Maciej Zdun DVM, PhD, Department of Basic and Preclinical Sciences, Institute of Veterinary Medicine, Nicolaus Copernicus University in Toruń, Lwowska 1, 87-100 Toruń, +48 5661122 31, e-mail: maciejzdun@umk.pl.

\section{Conflict of interest statement}

The authors declare they have no conflict of interest.

\section{References}

1. Hayward J, Baker M. A comparative study of the role of the cerebral blood in the regulation of brain temperature in five mammals. Brain Res. 1969;16:417-40; DOI:10.1016/0006-8993(69)90236-4.

2. Caputa M. Mechanizmy obrony mózgu przed przegrzaniem u człowieka i niektórych innych gatunków ssaków. Toruń: Roz UMK; 1982.

3. Strauss W, Hetem R, Mitchell D, Maloney S, O’Brien H, Meyer L, Fuller A. Body water conservation through selective brain cooling by the carotid rete: a physiological feature for surviving climate change? Conserv. Physiol. 2017; 5:1-15; DOI:10.1093/conphys/cow078.

4. Hetem RS, Strauss WM, Fick LG, Maloney SK, Meyer LCR, Fuller A Shobrak M, Mitchell D. Selective brain cooling in Arabian oryx (Oryx leucoryx): a physiological mechanism for coping with aridity? JEB. 2012;215(22):3917-24; DOI:10.1242/jeb.074666.

5. Krzymowski T, Skipor J, Grzegorzewski W. Cavernous sinus and carotid rete of sheep and sows as a possible place for countercurrent exchange of some neuropeptides and steroid hormones. Anim Rep Sci 1992;29;225-40.

6. Krzymowski T, Stefańczyk-Krzymowska S, Muszak J, Gilun P, Koziorowski M. Cavernous sinus and its mysterious physiological functions: facts and hypotheses Acta Biol Crac. 2014;55/56: 7-15.

7. McKenna M, Bell S. Classification of mammals above the species level. New York: Columbia University Press; 1997.

8. Graczyk S, Zdun M. The structure of the rostral epidural rete mirabile in selected representatives of the Cervidae and Bovidae families. Acta Zool. 2021;00, 1-6; DOI:10.1111/azo.12391.

9. Kiełtyka-Kurc A, Frąckowiak H, Nabzdyk M, Kowalczyk K, Zdun M, Tołkacz M. The arteries on the base of the brain in the camelids. Ital J Zool. 2014;81:215-20; DOI:10.1080/11250003.2014.901428.

10. Al Aiyan A, Menon P, Al Darwich A, Almuhairi F, Alnuaimi S, Bulshawareb A, Qablan M, Shehab S. Descriptive analysis of cerebral arterial vascular architecture in dromedary camel (Camelus dromedarius). Front Neuroanat. 2019;13:67; DOI:10.3389/fnana.2019.00067.

11. Jerbi H, Khalid S, Perez W. Morphometric study of the rostral epidural rete mirabile in the dromedary (Camelus dromedarius Linnaeus 1758). Int J Morph. 2016;34(4):1429-35; DOI:10.4067/ S0717-95022016000400042.

12. International Committee on Veterinary Gross Anatomical Nomenclature. Nomina anatomica veterinaria. 6th ed. Hannover: Editorial Committee Germany (Hanover), Belgium (Ghent), U.S.A. (Columbia), Brazil (Rio de Janeiro); 2017.

13. Simoens P, Lauwers H, De Geest J, De Schaepdrijver L. Functional morphology of the cranial retia mirabilia in the domestic mammals. Schweiz Arch Tierh. 1987;129:295-307.

14. Brudnicki W. Basilar arteries of the brain in domestic goat (Capra hircus). EJPAU 2000;3:2.

15. Dieguez G, Conde V, Gomez B, Iglesias J, Marin J, Lluch S. Rete mirabile of goat: in vitro effects of adrenergic stimulation. Brain Res. 1983;289:2814; DOI: 10.1016/0006-8993(83)90028-8.

16. Dieguez G, García A, Conde M, Gomez B, Santamaría L, Lluch S. In vitro studies of the carotid rete mirabile of Artiodactyla. Microvasc Res. 1987;33:143-54; DOI: 10.1016/0026-2862(87)90013-6.

17. Dieguez G, García-Villalón A, Gomez B, Lluch S. Hemodynamic significance of the carotid rete during changes in arterial blood pressure. Am J Physiol. 1988;254:770-5; DOI:10.1152/ajpregu.1988.254.5.R770.

18. O'Brein HD, Bourke J. Physical and computional fluid dynamics models for the hemodynamics of the artiodactyl carotid rete. J Theor Biol. 2015;386:122-31; DOI:10.1016/j.jtbi.2015.09.008.

19. Strauss AM, Hetem RS, Mitchell D, Maloney SK, Meyer LCR, Fuller A. Selective Brain Cooling Reduces Water Turnover in Dehydrated Sheep. PLoS One. 2015;10(2):e0115514; DOI:10.1371/journal.pone.0115514.

20. Grzegorzewski W, Skipor J, Wąsowska B, Krzymowski T. Counter current transfer of oxytocin from the venous blood of the perihypophyseal cavernous sinus to the arterial blood of carotid rete supplying the hypophysis and brain depends on the phase of the estrous cycle in pigs. Biol Reprod. 1995;52:139-44; DOI:10.1095/biolreprod52.1.139.

21. Skipor J, Wąsowska B, Grzegorzewski W, Zezula-Szpyra A, Stefańczyk-Krzymowska S, Triery J. Transfer of dopamine by counter-current mechanism in the ewes changes with endocrine stage. Biog Amin. 2001;16:431-45.

22. Skipor J, Wąsowska B, Picard S, Thiery J. Dopamine asses to the mediane eminence and brain throughout the vascular pathway in seep. Reprod Biol. 2004;4:91-106.

23. Khamas WA, Ghoshal NG, Bal HS. Histomorphologic structure of the carotid rete-cavernous sinus complex and its functional importance in sheep (ovis aries). Am J Vet Res. 1984;45:156-8. 
24. Grzegorzewski W, Skipor J, Wąsowska B, Krzymowski T. Countercurrent transfer of 125I-LHRH in the perihypophyseal cavernous sinus-carotid rete vascular complex, demonstrated on isolated pig heads perfused with autologous blood. Dom Ani Endoc. 1997;14:149-60; D0I:10.1016/ s0739-7240(97)00004-0.

25. Oren D. Humoral phototransduction: blood is messenger. Neuroscientist. 1996;2:207-10; DOI:10.1177/107385849600200408.

26. Gilun P, Stefańczyk-Krzymowska S, Romerowicz-Misielak M, Tabęcka-Lonczynska A, Przekop F, Koziorowski M. Carbon monoxide-mediated humoral pathway for the transmission of light signal to the hypothalamus. J Phys Pharm. 2013;64:761-72. 